\title{
Creating better humans towards sustainable competitive advantage for small and medium-sized accounting firms in Malaysia
}

\author{
Louis Lim Vui Han ${ }^{1,}$, Vijayesvaran Arumugam ${ }^{1}$, and Lawrence Arokiasamy ${ }^{1}$ \\ ${ }^{1}$ Faculty of Business \& Law, International University of Malaya-Wales, 50480 Kuala Lumpur, Malaysia
}

\begin{abstract}
This study will be a bit different than others in the sense that it pierces directly into the human hearts. The world current economy is full of mysterious and uncertainty. There are plenty of different perspectives, but who can guarantee that they are right? The root of the problems of all issues generally come from the human heart or action. If we able to deal with human issues, it sorts out almost all the problems. The purpose of this study is to determine the contributing factors towards the sustainable competitive advantage (SCA) of small and medium-sized accounting firms (SMPs) in Malaysia. It aims to have a long-term impact on the prospects for the practitioners and the accounting professions. It becomes an attention to the world when numerous accounting scandals being published, and they jeopardized the accounting professions' reputations. There are a few undisclosed cases especially it dealt with compliance, corporate tax, GST, money laundering and other issues, not only in Malaysia but in other countries as well. As such, the study focuses on creating better humans. Key findings from the literature highlighted the deficiencies in the core competencies of the firms. They are related to human capital and most of the researchers pinpointed the importance of knowledge, skills, capabilities in which it links to competencies in the corporate environment. The resource-based view of the firm is a common theory used by researchers as a mean of explaining competitive advantage and superior performance amongst the firms. And most of them stress the necessity to meet customer needs and expectation to create a sustainable competitive advantage.
\end{abstract}

Keywords: Sustainable competitive advantage, better humans, knowledge, skills, abilities, competencies, accounting firms, practitioners

\section{Introduction}

Doing business is exactly like going to the battlefield. The survivor wins. If you were dead, people forget you within three days. But if you survive, you always have a chance of success. There are various reasons for one person to be successful, but there are almost the same reasons for people to fail - greedy, wrong team, run too fast with too much money. Learn to face these mistakes and troubles when it arrives (Quote by Jack Ma). It is the reason why business sustainability is very important.

The role and tasks of the accounting profession have changed after numerous accounting scandals such as Enron, WorldCom, Tyco and others occurred in year 2000s. As a result, the Organisation for Economic Cooperation and Development (OECD) determines in its mission promoting policies that will improve the economic and social well-being of people around the world.

Corporate Governance was introduced as compliance for companies in many countries including Malaysia. It serves as a deterrent to future unhealthy growing issues after the unexpected accounting scandals. SMPs must equip themselves with solid amour to face the challenge ahead.

The quote in Sun-Tzu War of Management states "know yourself know your enemy, one will win the battle. Know the weather know the climate, the victory shall be yours." In short, the SMPs has to be prepared before they are affected, or it will be too late.

\footnotetext{
* Corresponding author: louisvuihan @ gmail.com
} 
Siti-Nabiha, Scapens, (2005) revealed that change is inevitable and is not necessarily contradictory and opposing forces. The accounting profession must be innovative and competent in the evolutionary process of change.

Brian Blood, Chief Executive of Confederation of Asian and Pacific Accountants (2016) addressed the role of accounting in powering economic prosperity in Asia at the second Financial Reform for Economic Development Forum (FRED II) and conclude the need for strong public financial management and the importance of professional accountancy organisations in engaging with the public sector to bring about change, noting that "good decision making is founded on good information".

In recent years, there has been a growing need in Asian countries to appreciate the roles of SMPs in the accounting industry. It is simply because many practitioners in these countries are comprised of SMPs who employ professional accountants and contribute to employment creation in the industry. Another reason is SMPs are greatly engaged to provide valuable business support to small and medium enterprises (SMEs) (Williams, O'Donovan, 2015) which are currently considered as the engines of economic development both in developed and developing countries.

In Malaysia, there is no exception in leniency of accounting practices in the market. The Ministry of Finance has set up the Committee to Strengthen the Accountancy Profession (CSAP), which aims at addressing the strategic challenges facing the accounting profession in the country. Hence, an accountant's knowledge is priceless when assessing an organisation's financial health and performance. Whether it is a small firm or a multinational corporation, accounting professions are depended upon in steering the business towards success.

\section{Research problems}

The study focuses on creating better humans towards SCA for SMPs in Malaysia. Creating better humans refer to developing knowledge, skills and abilities (KSA) which are the core competency skills include communication skills, interpersonal skills, general business knowledge, accounting knowledge, problem-solving skills, information technology and computer skills, and personal attitudes and capabilities.

The international scandals have put the accounting profession under public and regulatory scrutiny. The public's perception of the accounting profession has changed, putting high expectation on them to lend credibility to publish financial reports (Zabihollah, 2004) and be always in high competency level. Accordingly, restoring public confidence in auditors' judgments and reputation is necessary. Accountants must align themselves with strategic ways to adhere to the compliance issues. In addition, the accounting professions were under a strict monitoring of Malaysian Audit Oversight Board (AOB) and Malaysian Institute of Accountants (MIA). Therefore, the better humans cannot be overlooked and more competent accountants are needed in the market.

Consequently, the accounting professional landscape is continuously changing, particularly the new laws and auditing standards. The accountant needs to develop the habit to regularly update themselves with the latest information (Palmer, Ziegenfuss, Pinsker, 2004). It pinpointed that in addition to general business knowledge and accounting knowledge, personal attitudes towards the learning capabilities and initiatives are also significant.

Francis, (1994), cited in Nagy, Cenker, (2007) added that those changes lead to the works of accounting professions to be structured and standardized, but has limited their subjectivity. Lack of conceptual skills and professional judgment capabilities disqualify them to stay relevant not only in Malaysia but also across international borders. For instance, a Malaysian firm doing business with multinational clients which have subsidiaries overseas. Not simply only that, the general business knowledge and personal attitudes and capabilities are questionable too. It is clearly due to the internal weaknesses of the SMPs. These core competency skills fall part of the KSA mentioned earlier.

It is without a doubt that the tight laws, principles and regulations are secure for the industries. However, external auditors experienced increased stress because of increased expectation of independence. A lot of compliance work restricted higher audit fees and greater reporting responsibility add on stress on them. Stress management and self-responsibility practices within the workplace will create accountability and leadership accomplishments. But Nagy, Cenker, (2017) suggested that a good communication skill to bridge the tension of auditors/client relationship during the long meeting and regular dialogues will create a competitive advantage to the practitioners. Communication skills, interpersonal skills, and personal attitudes and capabilities are internal weaknesses to be improved.

McDowall, Jackling (2010), Bunea (2017), Marriott and Marriott, (2003), found that the lack of core competencies start from the students in colleges and universities affecting communication skills, interpersonal skills, general business knowledge, accounting knowledge, problem-solving skills, information technology and computer 
skills, and personal attitudes and capabilities. The educators have crucial roles to reverse the effects. There is a gap between the KSA in the present state of accounting education as perceived by practitioners and educators in Malaysia (Abdul Aziz, Abdul Rahim, Mohamed Shith, 2010).

Janvrin D., Bierstaker J., and Lowe J. D., (2009) asserted that whether it is auditors or the clients, the use of information system (IS) tools is a norm in the technology world. Ahmi, Saidin, Abdullah, (2014) however, implied that if they have not fully adopted IS, they should at least be in the process of adoption or having a positive perception towards technology usage. It is unknown exactly how powerful new technology will change our lives and works. One thing for sure is that technologies will take over more and more routine tasks, so our goal must keep creating new tasks that are not routine.

The appropriate research question is, therefore: What are the major factors contributing to SCA for SMPs? Hence, the research objective is to identify the major factors contributing towards SCA for SMPs.

\section{Literature review}

The literature review must bring clarity and focus to the research problem, improving the research methodology, broadening the knowledge base in the research area and with the hope of enabling to contextualize any findings.

\subsection{Sustainable competitive advantage}

The strategic management is a plan of action designed to achieve a long-term or overall design using the allocated available resources (Chandler, 1962). It would be pointless if the strategy could not address the internal and external issues affecting the organisation. This is what we want to do and how we intend to do which enable the organisation to adopt the master plan in the future (Abell, 1993).

Dess, Lumpkin, Eisner, McNamara, (2014) in the book 'Strategic Management', 7th Edition, McGraw Hill, Chapter 1, state that competitive advantage is a firm's resources and capabilities that enable it to overcome the competitive forces in the industry. However, it is the best to determine how a firm is to compete that are sustainable over a length of time. The firm should position itself to minimize its costs of service or develop services that are unique for customers and will enable the firm to charge at premium prices.

Sustainable competitive advantage can be achieved by enhancing the operational effectiveness and competitive dynamic. It is directed at overall organizational goals, includes multiple stakeholders, incorporates both short-term and long-term perspectives, and merges trade-offs between efficiency and effectiveness.

Competitive advantages provide an edge over rivals and an ability to generate greater value for a firm and its shareholders. The more sustainable the competitive advantage, the more difficult it is for competitors to neutralize the advantage. The two main types of competitive advantages are comparative advantage and differential advantage.

Comparative advantage is generated by a firm's ability to produce a good or service at a lower cost than its competitors. This gives the firm the ability to sell its goods or services at a lower price than its competitors or to generate a larger margin on sales. Rational consumers will choose the cheaper of any two perfect substitutes offered. If the effects of comparative advantage are partially offset by imperfect substitution, higher margins for the lowestcost producers will eventually benefit shareholders through superior returns or provide the company with more resources for marketing, research and development or administrative infrastructure improvements to support future growth.

Comparative advantage can be derived from economies of scale, more efficient internal systems, location in geographies with low labour or low property expenses. These do not always imply the company can produce a better product or service, but rather they can offer a product or service at a lower price. In the context of international trade economics, comparative advantages are determined by opportunity cost, and any part has a comparative advantage at something.

A differential advantage is created when a firm's products or services differ from its competitors and are superior to a competitive offering. Differential advantages can be driven by more advanced technology, patentprotected products or processes, superior personnel, or a strong brand identity. These factors support wide margins and large market shares.

Hill, Jones, (2008) stressed the approach of a mission to meet the need for a customer-oriented rather than a product-oriented business. The customer-oriented business derives from the questions of 'who is being satisfied?', 'what is being satisfied?', and 'how customer needs are being satisfied?'. It focuses on customer groups, customer needs and distinctive competencies. 
Williams, O'Donovan, (2015) questioned the deficiencies in the effectiveness of the accounting profession in supporting SMEs in implementing Small Business Practitioners (SBPs) despite a request from clients for accountants to provide this advice. It is a belief that accountants are best placed to do so. The SMPs should create competitive advantage by priorities more of its quality time with the customers and assist to solve the doubts of the clients. The results show the potential benefits of implementing SBPs which include improved customer loyalty, cost savings and reduced risk of government-posed regulation.

In explaining sustainable competitive advantages, the literature by Johannessen, Olsen, (2009) showed two major paradigms, the industrial organization (IO) theory and the resource-based perspective. They explained that the firms need to exert monopoly power to make supernormal profits. They are possible by limiting competitive forces through creating entry barriers at the industry level.

\subsection{Better humans - Knowledge, skills and abilities (KSA)}

Again, creating better humans refer to the knowledge, skills and abilities of human capital. There are various works on core competencies that support the essence of knowledge, skills, and abilities in knowledge management systems and theories. Palmer et al., (2004) concluded the common and specialized competencies are related to knowledge, skills, and abilities which can be used by any interested parties to design hiring and evaluation aspect. The components are communication skills, interpersonal skills, general business knowledge, accounting knowledge, problem-solving skills, information technology and computer skills, personal attitudes and capabilities.

Table 3.1

\begin{tabular}{|c|c|c|}
\hline Study title & Organization & Year completed \\
\hline $\begin{array}{l}\text { Perspectives on education: capabilities for success in } \\
\text { the accounting profession (The Big Eight White } \\
\text { Paper) }\end{array}$ & Big Eight firms & 1989 \\
\hline $\begin{array}{l}\text { Objectives of education for accountants: accounting } \\
\text { education change commission position statement } \\
\text { number one }\end{array}$ & AECC & 1990 \\
\hline $\begin{array}{l}\text { What corporate America wants in entry-level } \\
\text { accountants }\end{array}$ & IMA & 1994 \\
\hline $\begin{array}{l}\text { The } 1996 \text { practice analysis of management } \\
\text { accounting }\end{array}$ & IMA & 1996 \\
\hline $\begin{array}{l}\text { Competence-based approaches to the professional } \\
\text { preparation of accountants }\end{array}$ & IFAC & 1998 \\
\hline $\begin{array}{l}\text { The } 1999 \text { practice analysis of management } \\
\text { accounting }\end{array}$ & IMA & 1999 \\
\hline Competency framework for internal auditing & ПА & 1999 \\
\hline $\begin{array}{l}\text { The AICPA core competency framework for entry } \\
\text { into the accounting profession }\end{array}$ & AICPA & 1999 \\
\hline Towards competent professional accountants & IFAC & 2003 \\
\hline
\end{tabular}

The organization in the Table 3.1 list out the research topics carried out and its completed year. The result from the authors on its comparison of the various competency studies as to whether they are the important criteria for the competency level in the practical world is shown in Table 3.2 below.

Table 3.2

\begin{tabular}{|c|c|c|c|c|c|c|c|c|}
\hline & White Paper & AECC & AECC & $\begin{array}{l}\text { Studies } \\
\text { IMA }\end{array}$ & IMA & ILA & AICPA & IFAC \\
\hline Communications skills & $\mathrm{X}$ & $\mathrm{X}$ & $\mathrm{X}$ & $\mathrm{X}$ & $\mathrm{X}$ & $\mathrm{X}$ & $\mathrm{X}$ & $\mathrm{X}$ \\
\hline Interpersonal skills & $\mathrm{X}$ & $\mathrm{X}$ & $\mathrm{X}$ & $\mathrm{X}$ & $\mathrm{X}$ & $\mathrm{X}$ & $\mathrm{X}$ & $\mathrm{X}$ \\
\hline General business knowledge & $\mathrm{X}$ & $\mathrm{X}$ & $\mathrm{X}$ & $\mathrm{X}$ & $\mathrm{X}$ & $\mathrm{X}$ & $\mathrm{X}$ & $\mathrm{X}$ \\
\hline Accounting knowledge & $\mathrm{X}$ & $\mathrm{X}$ & $\mathrm{X}$ & $\mathrm{X}$ & $\mathrm{X}$ & $\mathrm{X}$ & $\mathrm{X}$ & $\mathrm{X}$ \\
\hline $\begin{array}{l}\text { Problem-solving skills } \\
\text { (intellectual skills) }\end{array}$ & $\mathrm{X}$ & $\mathrm{X}$ & $\mathrm{X}$ & $\mathrm{X}$ & & $\mathrm{X}$ & $\mathrm{X}$ & $\mathrm{X}$ \\
\hline Information technology & $\mathrm{X}$ & $\mathrm{X}$ & $\mathrm{X}$ & & $\mathrm{X}$ & $\mathrm{X}$ & & $\mathrm{X}$ \\
\hline $\begin{array}{l}\text { Attitudes, capabilities } \\
\text { professionalism }\end{array}$ & $\mathrm{X}$ & $\mathrm{X}$ & $\mathrm{X}$ & & $\mathrm{X}$ & $\mathrm{X}$ & & $\mathrm{X}$ \\
\hline Computer skills & $\mathrm{X}$ & $\mathrm{X}$ & $\mathrm{X}$ & $\mathrm{X}$ & & & & $\mathrm{X}$ \\
\hline Leadership & $\mathrm{X}$ & & & & $\mathrm{X}$ & & & $\mathrm{X}$ \\
\hline
\end{tabular}




\subsubsection{Communication skills}

Johannessen, Olsen, (2009) pointed out the importance of innovation as a process of percolation. There are two classes of forces termed as connectivity and receptivity. Connectivity can be used among the agents in the network, and receptivity can be used by each agent's capacity to absorb the information received. In short, it is concluded that proactive firms have a greater extent of adaptation, more external connectivity and a better integration of electronic data interchange information. Information richness theory (Daft, Lengel, 1986, cited in Johannessen, Olsen, 2009) argued that communication media vary in their capacity to process rich information. It may differ in its richness through face-to-face, telephone, personal documents such as letters and memos, impersonal written documents, and numeric documents. Lee, (1994) supported the view of information richness theory that electronic mail may filter out important cues such as body language and tone of voice and, unlike face-to-face meetings, is not conducive to immediate feedback.

Stone, (2011) emphasised that accountants who adopt communication approaches with small managers must prove its needs of the economical significant in the small business sector. Colbert, (2002) acknowledged the communication as significant for internal and external auditors after the required implementation of corporate governance, together with both the International Standards of Auditing (ISAs) and the Practice Advisories (PAs).

\subsubsection{Interpersonal skills}

Interpersonal skills have the positive effects of work engagement on outcome measures of transformational leadership and leader well-being at work (Mencl, Wefald, \& Ittersum, 2016). It consists of emotional and political skills, in which results show that they are important capability contributing to transformational leadership and leaders' job satisfaction. Transformational leadership is well aligned with management in the modern knowledge economy because of the nature of work is characterized by personal interactions and meet individualized needs. Organisations will benefit from implementing ways to engage managers in their work to facilitate transformational leader behaviours and well-being.

Sahai, Jain, Bahguna, (2014) pinpointed that bridging the gap using training in interpersonal communication helps in improving customer service experience. The functional fluency model helps in identifying the dominant response style and the variables emergent for a group of frontline staff. This can help in designing training programs that will assist employees in enhancing their interpersonal communication from positive functioning and being cautious or exercise restraint on the negative functioning of functional fluency model.

\subsubsection{General business knowledge and accounting knowledge}

Razaee, (2004) reminded the accounting professions to lend credibility to publish financial reports. They must rebuild and restore public confidence in auditors' judgments and reputation. Therefore, SMPs must change their attitude toward managing firms with integrity and transparency. In the meantime, they have to improve their capabilities to absorb additional knowledge (general business knowledge and accounting knowledge) and enhance other competencies skills. The perceptions of corporate governance, auditing standards, accounting standards, acts and regulations etc. should be taken positively as an opportunity to strengthen the core competencies to create a sustainable competitive advantage.

\subsubsection{Problem-solving skills}

Glover, Champion, Daniels, Boocock, (2016) using capital theory to explore problem-solving and innovation in small firms revealed that firms which possess higher levels of social and cultural capital have a higher success rate in problem-solving and are more likely to engage in the innovative activity. Social and cultural capitals complement and reinforce one another in small firms, enhanced the ability to utilize networks and to access a greater diversity of knowledge.

\subsubsection{IT and computer skills}

Katamba, Angelina Yee, How, Hsin, (2017) stressed the critical of audit firms to adopt different technologies to support their activities. By doing so, they will improve the competency level to build public confidence in them. 
Gary Pan, Sayyen Teoh, Poh, (2014) identified two actions that were instrumental in enriching resources in IT capability development process which are collective leadership and managing change. Additionally, three attributes supported the resource-enrichment process are effective governance structure, extensive IT knowledge and business experience, and stakeholder commitment.

\subsubsection{Personal attitudes and capabilities}

Miikka, Theo, Tuuli, (2017) in their study found that self-management practices have a larger impact on the quality and quantity of individual performance. As Bunea (2017) has commented since study time, students prefer judgments made in financial accounting rather than for management purposes which indicates the attitudes towards persuasion skills, critical thinking skills, interdisciplinary thinking skills and decision-making skills need to change. If not, the capabilities of them at the workplace are questionable.

\subsection{Relationship between SCA and KSA}

Companies of all sizes and industries are undergoing a digital transformation. They are developing operations and overhauling infrastructure to better attend to clients, partners and employees and to respond more rapidly in shifting market conditions.

Simple tools allow business users to design and adapt their own process. Dynamic processes allow people to break out the rigid workflows and collaborate on issue resolution. The integration of the content with the process adds intelligence to automated information flows so employees work more efficiently and effectively.

\subsubsection{Theories and models}

Fang Huang, Gardner, Moayer, (2016) highlighted the key components and applications of the new strategic knowledge management (SKM) conceptual model for actively integrating explicit and tacit knowledge rooted within the organization systems and bigger social business intelligence networks. It aligned managerial practices by enabling organizational learning, building organizational memory, encouraging knowledge sharing and collaborative decision support (Liao, 2003, cited in Fang Huang, et al., 2016).

At today's peak of competition, business process management (BPM) is viewed as a best practice management principle that can help companies in sustaining competitive advantage. Established on the reassessment of the literature, the study of BPM can be analysed based on the dynamic capability theory (Nadarajah, Abdul Kadir, 2014). Process alignment and the people involved are the focal points. They are based on a few theories such as systems theory, organizational theory, alignment theory and strategic theory. The results indicated that when systems, process and people are perfectly aligned, it can work to harness the organisation's sustainability.

The BPM life cycle in Figure 3.1 shows the flow of the process from design to optimization.

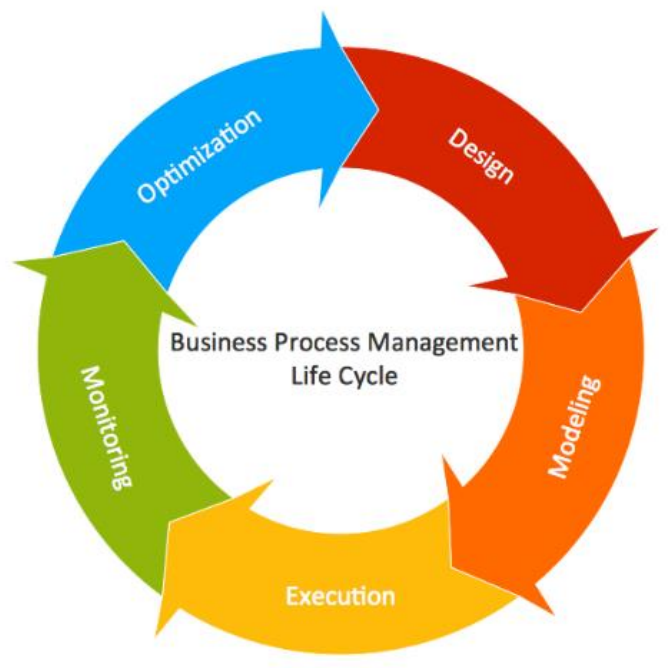

Figure 3.1: Business Process Management Life Cycle 
Remy, Dai, (2009), on the other hand, found that the perceived importance of knowledge management activities, especially the combination, appears as an important source of competitive advantage related to technical knowledge. More time spent on knowledge management tasks, socialisation, contributes to a competitive advantage related to affective knowledge. They use the knowledge-creation theory based on this paradigm that all knowledge can be classified as either tacit knowledge (Polanyi, 1966) or explicit knowledge. On one hand, tacit knowledge is the cognitive knowledge that is hard to express with language or numbers: for example, beliefs, points of view, technical skills and know-how are all part of tacit knowledge. On the other hand, explicit knowledge is the objective and rational knowledge that can be expressed with language or numbers: texts, equations, specifications and manuals are a few examples.

Nagy, Cenker, (2007) however, observed that the increase in oversight board monitoring and workload have changed the nature of the external audit function to more compliance type work, and the environment has created much concern for the auditors. The new reform has significantly impacted the audit environment in terms of scope of services, client assessment procedures, management and audit committee relationships with the external auditors, audit firm personnel management, and the long-term outlook of the profession. It means that the strategy must focus on improvement in operational activities.

Adams, Lamont, (2003) further suggested that firms must learn to re-bundle internal competencies and resources to maintain competitive advantages over time. Applying the resource-based view of the firm and dynamic capabilities perspectives, the roles that absorptive and transformative capacity played in the organizational innovation with specific emphasis placed on the role and effectiveness of knowledge management systems is a determinant of innovative practices.

Due to that reason, Manson, McCartney, Sherer, (2001) pointed out that audit automation cannot be viewed simply as a technology for improving the quality and/or productivity of the audit process. It has value as a symbol of the firm's market competitiveness and hence helps to promote the firm to clients internally. In addition, the research shows that audit automation offers considerable opportunities for greater managerial surveillance and control, but it facilitates a less hierarchical and more informal organisational structure.

Burden, Proctor, (2000) asserted that meeting customer's need on a timely basis and it is everyday routine for achieving and sustaining competitive advantage. The secret is to employ training as a tool to succeed. They argued that customers' needs are often not given the care they merit. There is the potential for enhancing practice on the ability to relate customer satisfaction to organizational objectives and the ability to enforce the behavioural changes necessary to accomplish these objectives. They proposed that it is helpful to refer to the PROMPT model which are:

$$
\begin{array}{ll}
\mathrm{P} & \text { prioritizing customer need } \\
\mathrm{R} & \text { reliable service delivery } \\
\mathrm{O} & \text { organizing for customers } \\
\mathrm{M} & \text { measuring customer satisfaction } \\
\mathrm{P} & \text { personnel training } \\
\mathrm{T} & \text { technology focusing }
\end{array}
$$

According to Philips, (1991), cited in Burden, Proctor, (2000), evaluation is undertaken to improve the human resource development (HRD) process and to decide whether to continue it. It is part of monitoring and control.

Social exchange theory (SET) provides an explanation of how we believe mentor challenges could influence knowledge sharing (KS) both directly and indirectly through their effect on organizational commitment. This theory proposes that human behaviour and decision-making are driven by an individual's expectation of costs and benefits arising from interpersonal exchanges (Blau, 1964 cited in Curtis, Taylor, 2018). Through developmental mentoring, effective organizational commitment and KS in public accounting firms, it would encourage employees to share their knowledge with others at work. 


\section{Conclusion and implication}

The 2017 Data \& Analytics Report of MIT Sloan Management Review found that the percentage of companies deriving competitive advantage from analytics increased for the first time in four years. Incorporating survey results and interviews with practitioners and scholars, the report found that companies' increasing ability to innovate with analytics is driving a resurgence of strategic benefits from analytics across industries. The report is based, in part, on MIT SMR's seventh annual data and analytics, global survey, which includes responses from 2,602 business executives, managers, and analytics professionals from organizations located around the world (Sam Ransbotham and David Kiron, 2017).

Organisations have been stimulating a critical reflection about the factors that affect the performance of the individual and of the organisations themselves (Ribeiro, Soares, Abranches, Ziviami, 2018). This study just fitted into their claim that knowledge became one of the main organisational competitive factors, and knowledge management could contribute as an enhancer for organisational results. Furthermore, the changing nature of the business environment is the major influence on the performance and the process needs to be continuously and consistently assessed (Abdul Aziz et al., 2010).

In the organisational theory, it is the study of organisational behaviour. There are three key areas which could stem the SCA of an organisation. They are leadership, organisation culture and organisation structure. Leadership is the key factor and superior to the others to ensure the strategy formulation and implementation are successfully and effectively work out for the organisation. Effective leadership, therefore, drives employees' competencies level to create the organisation's competitive advantage. Leaders, on the other hand, could instil the practices and beliefs of becoming the organisation culture.

The intent of the study reaffirms what are the existing problems that affect the industry. The predicted outcome is that the major competency factors of KSA significant towards SCA for SMPs. Another resolution to the problems is the organizational culture.

Culture is what people do with the world. But clearly more needs to be said as not everything we do becomes part of the culture. For example, people commit murder and that behaviour is seen as criminal and antisocial. In short, there is something not right with the culture we are living in now. According to sociologist Peter Berger, "Every human society is an enterprise of world-building." We build bridges to connect islands to the mainland so that we can build houses, shops, universities and theatres there. We make movies to show in theatres, so we can overcharge for popcorn. We call this externalization. Humans externalize their values, imaginations, innovations, and ideas on the world around them by what they do. Most of what we do is consistent with our culture, but not always. That is why cultures change, new things are created, and old things are left behind.

When what we do becomes part of our normal way of living together, it is called objectification. Culture is the environments we create for ourselves. What is normal in a place is not necessarily normal in another place. The power of what we experience as normal, though largely unnoticed until we experience the different, determine much in our daily lives. Internalization is the word for how culture shapes us. We internalize culture as we settle into its routines, lifestyles, and habits.

To summarise, culture consists of human activities that have collectively taken on a life of their own. In other words, we make our cultures, and then our cultures shape us. It is an awareness to change the culture for a better future in creating better humans. Yes, as an individual alone, it may sound absurd and impossible to realise this. Effective leaders could, you could, and all Malaysians could if everyone plays its part with courage.

Critically, an employee's performance is the issue of the study. We have to know self-determination theory. It is the study of human motivation and personality, but unfortunately, people management is the hardest skill to master. Our study has given the insights of better humans i.e. competences of KSA. If the leaders of an organization could enforce the improvement of the employees into high competence, it is assured of the SCA for SMPs.

\section{The limitation of the study}

The study focuses on the core values of SMPs at micro-level of fundamental elements. Macro-level issues in respect of the political environment, economic environment, social influence, technology change, legal perspective and environmental change are equally important. Sisaye, (2013) found that the accounting reports on sustainability need to address the economic, environmental, and social performance of corporations. She further commented that organisational ecology has shaped environmental factors, organizational structures, technology developments, government regulatory agencies, and cultural and social forces. The scope to extend this study to include the macro level factors is very difficult due to time constraint. It is suggested that further in-depth research is necessary to 
combine micro and macro factors which may help to enhance the sustainability of the accounting profession competitive advantage in a more dynamic way.

The study of better humans related to human nature is undoubtfully important. However, the individual and organization behaviour varies from individual to individual, and from organization to another organization.

The research scope covers SMPs in Malaysia only and excludes the big-sized practitioners. Although generally, it looks relevant to big-sized firms as well, however, it needs further research to ascertain its applicability.

The respondent target is accounting professions. Population and sampling would exclude accounting students from colleges and universities. Respondents from accounting professions at workplace deemed to be representative.

\section{Practical contributions}

There are two external forces that lead to the significance of this study. First, international scandals have put the accounting profession under public and regulatory scrutiny. The public's perception of the accounting profession has changed putting high expectation on them to lend credibility to published financial reports (Zabihollah Razaee, 2004) and be always in high competency level.

Organisation for Economic Co-Operation and Development (OECD) emphasized to strengthen the market discipline and to improve corporate governance practices by adopting international accounting, audit and financial disclosure standards and practices will facilitate transparency, as well as comparability of information across different jurisdictions. All accounting practitioners must have the right attitudes to update themselves and adopt the practices required. The changing of accounting landscape, i.e. new laws, standards and regulations, from time to time is a good initiative for the industries. However, it would not be effective if the practitioners do not put effort into the change.

Second, SMEs are an integral component of economies which at least representing more than $90 \%$ of businesses in most of the countries worldwide. In Malaysia, SMEs cover more than $98 \%$ of all business establishments. Williams, O'Donovan, (2015) highlighted that the accounting profession's deficiencies in effectiveness to assist SMEs with the adoption of sustainable business practices (SBPs) and suggested that the level of accounting professions involvement in assisting SMEs to close up the expectations gap or these SMEs will likely seek advice and support from other professions.

Employers spend millions of Ringgits per year in process optimisation, technology and tools to boost performance and profitability. Yet the workforce using them at below optimal level of productivity.

To make the situation worse, McDowall and Jackling, (2010) in their study on attitudes towards the accounting profession, found that the number of students majoring in accounting has declined and impacted the supply of accounting profession. The educators should play an important role to potentially reverse the effect of negative perceptions of the profession observed by Mladenovic (2000), cited in McDowall and Jackling, (2010), and evidence from Marriott and Marriott (2003) that accounting studies have a negative effect on the attitudes.

\section{Theoretical contributions}

There is no research done on better humans in regards to knowledge, skills and abilities towards the sustainable competitive advantage of small and medium-sized accounting firms in Malaysia. The closest research done was "Coordinating the processes of resource enrichment and capability deployment lessons from IT implementation at a medium-sized accounting firm” by Gary Pan, Sayyen Teoh, Sun Seow, (2014) from Singapore.

This study refers SMPs to not specifically for accounting firms only, but also to include audit firms, taxation firms, secretarial firms and finance and accounts related consultancy firms. It is the opportunity to ascertain the relevance of available theories used in the literature reviews to the targeted group of study.

Some of the researchers' findings suggesting that knowledge management strategies should be tailored to fit the discriminate beliefs and actions of each group of employees, identified based on their level of comparison between their adopted theories and theories-in-use related to knowledge management.

There was a research by Palmer et al., (2004) on "International knowledge, skills, and abilities of auditors/accountants: Evidence from recent competency studies ". The resources were compiled from the completed study by respective professional firms and bodies from 1989 to 2003.

With a global economy that is changing at a speed with an intensity that seems remarkable, the accounting profession will undoubtedly be greatly impacted by more regulations, digital technologies, stronger demand for governance and greater harmonization of standards. The study will show that the nature of better humans i.e. KSA 
will contribute towards the competitive advantage sustainability of SMPs in Malaysia. The findings would be of great help for this industry to position themselves to create a competitive advantage in the current highly competitive environment. 


\section{References}

A.K. Siti-Nabiha, Robert W. Scapens, (2005) "Stability and change: an institutionalist study of management accounting change", Accounting, Auditing \& Accountability Journal, Vol. 18 Issue: 1, pp.44-73, https://doi.org/10.1108/09513570510584656

Abdul Aziz Rozainun, Abdul Rahim Memiyanty, Mohamed Shith Putera, (2010) "Better skills? Better service?: Malaysian evidence", 2010 International Conference on Financial Theory and Engineering

Abell, D. F., (1993) "Managing with Dual Strategies: Mastering the Present - Preempting the Future", Simon and Schuster, https://www.toolshero.com/strategy/abell-model/

Aidi Ahmi*, Siti Zabedah Saidin, Akilah Abdullah, (2014) "IT adoption by internal auditors in public sector: A conceptual study", International Conference on Accounting Studies 2014, ICAS 2014, Procedia - Social and Behavioral Sciences 164 (2014) 591 - 599, https://doi.org/10.1016/j.sbspro.2014.11.151

Albert L. Nagy, William J. Cenker, (2007) "Accounting firms cautiously maneuver in the new audit environment - a note", Managerial Auditing Journal, Vol. 22 Issue: 2, pp.218-225, https://doi.org/10.1108/02686900710718690

Alfred D. Chandler. Jr., (1962) "Strategy and Structure: Chapters in the History of the Industrial Enterprise”, M. I. T. Press Research Monographs, (Cambridge, Mass.: M. I. T. Press. 1962. Pp. xiv, 463, https://doi.org/10.1086/ahr/68.1.158

Asha Baleche Katamba, Angelina Yee Seow Voon, How Shi Min and Hsin Vonn Seow, (2017) "Information Systems Utilisation by External Auditors in Tanzania", Review of Integrative Business and Economics Research, Vol. 6, Issue 4 377, Copyright 2017, GMP Press and Printing, ISSN: 2304-1013 (Online); 2304-1269 (CDROM); 2414-6722 (Print), http://buscompress.com/journal-home.html

Belinda Rachael Williams, Gary O'Donovan, (2015) "The accountants' perspective on sustainable business practices in SMEs", Social Responsibility Journal, Vol. 11 Issue: 3, pp.641-656, https://doi.org/10.1108/SRJ-07-2014-0096

Dess, Lumpkin, Eisner, McNamara, (2014), Strategic Management - text and cases, $7^{\text {th }}$ Edition, McGraw Hill, ISBN 978-0-07-786252-7

Devika Nadarajah, Sharifah Latifah Syed Abdul Kadir, (2014) "A review of the importance of business process management in achieving sustainable competitive advantage", The TQM Journal, Vol. 26 Issue: 5, pp.522-531, https://doi.org/10.1108/TQM-01-2013-0008

Diane Janvrin, James Bierstaker, and D. Jordan Lowe, (2008) "An Examination of Audit Information Technology Use and Perceived Importance." Accounting Horizons: March 2008, Vol. 22, No. 1, pp. 1-21. https://doi.org/10.2308/acch.2008.22.1.1

Fang Huang, Scott Gardner, Sanaz Moayer, (2016) "Towards a framework for strategic knowledge management practice: Integrating soft and hard systems for competitive advantage", VINE Journal of Information and Knowledge Management Systems, Vol. 46 Issue: 4, pp.492-507, https://doi.org/10.1108/VJIKMS-08-2015-0049

Gary Pan, Sayyen Teoh, Poh Sun Seow, (2014) "Coordinating the processes of resource enrichment and capability deployment: Lessons from IT implementation at a medium-sized accounting firm", International Journal of Accounting \& Information Management, Vol. 22 Issue: 4, pp.357-374, https://doi.org/10.1108/IJAIM-07-2013-0043

Garry L. Adams, Bruce T. Lamont, (2003) "Knowledge management systems and developing sustainable competitive advantage", Journal of Knowledge Management, Vol. 7 Issue: 2, pp.142-154, https://doi.org/10.1108/13673270310477342

Gerard Stone, (2011) "Let's talk: Adapting accountants 'communications to small business managers' objectives and preferences", Accounting, Auditing \& Accountability Journal, Vol. 24 Issue: 6, pp.781-809, https://doi.org/10.1108/09513571111155546 
Hill, Jones, (2008), Strategic Management Theory - An integrated approach, $9^{\text {th }}$ Edition, South-Western Cengage Learning, ISBN 978-0-538-75107-0

International Federation of Accountants (IFAC), Finance Leadership \& Development - The Role of Accounting in Powering Economic Prosperity in Asia by Brian Blood, Chief Executive, Confederation of Asian and Pacific Accountants and Jackie Poirier, President, Confederation of Asian and Pacific Accountants (September 2, 2016).

Jane Glover, Donna Champion, Kevin Daniels, Grahame Boocock, (2016) "Using capital theory to explore problemsolving and innovation in small firms", Journal of Small Business and Enterprise Development, Vol. 23 Issue: 1, pp.25-43, https://doi.org/10.1108/JSBED-02-2014-0033

Janet L. Colbert, (2002) "Corporate governance: communications from internal and external auditors", Managerial Auditing Journal, Vol. 17 Issue: 3, pp.147-152, https://doi.org/10.1108/02686900210419930

Jennifer Mencl, Andrew J. Wefald, Kyle W. van Ittersum, (2016) "Transformational leader attributes: interpersonal skills, engagement, and well-being", Leadership \& Organization Development Journal, Vol. 37 Issue: 5, pp.635-657, https://doi.org/10.1108/LODJ-09-2014-0178

Jon-Arild Johannessen, Bjørn Olsen, (2009) "Systemic knowledge processes, innovation and sustainable competitive advantages", Kybernetes, Vol. 38 Issue: 3/4, pp.559-580, https://doi.org/10.1108/03684920910944795

Kristine N. Palmer, Douglas E. Ziegenfuss, Robert E. Pinsker, (2004) "International knowledge, skills, and abilities of auditors/accountants: Evidence from recent competency studies", Managerial Auditing Journal, Vol. 19 Issue: 7 , pp.889-896, https://doi.org/10.1108/02686900410549411

Mary B. Curtis, Eileen Z. Taylor, (2018) "Developmental mentoring, affective organizational commitment, and knowledge sharing in public accounting firms", Journal of Knowledge Management, Vol. 22 Issue: 1, pp.142-161, https://doi.org/10.1108/JKM-03-2017-0097

Miikka Palvalin, Theo van der Voordt, Tuuli Jylhä, (2017) "The impact of workplaces and self-management practices on the productivity of knowledge workers", Journal of Facilities Management, Vol. 15 Issue: 4, pp.423438, https://doi.org/10.1108/JFM-03-2017-0010

Rebecca Burden, Tony Proctor, (2000) "Creating a sustainable competitive advantage through training", Team Performance Management: An International Journal, Vol. 6 Issue: 5/6, pp.90-97, https://doi.org/10.1108/13527590010348200

Remy Magnier-Watanabe, Dai Senoo, (2009) "Congruent knowledge management behaviors as discriminate sources of competitive advantage", Journal of Workplace Learning, Vol. 21 Issue: 2, pp.109-124, https://doi.org/10.1108/13665620910934816

Ribeiro, Jurema Suely de Araújo Nery; Soares, Marco Antônio Calijorne; Jurza, Paulo Henrique Abranches; Ziviani, Fabrício, (2018) "The articulation between innovation and competences anchored by knowledge management aiming sustainable competitive advantage.” Brazilian Journal of Information Science: Research Trends. 12:2 (2018) p.52-63. ISSN 1981-1640.

Sam Ransbotham, David Kiron, (2017) “Analytics as a source of business innovation” MIT Sloan Management Review, https://sloanreview.mit.edu/big-ideas/data-analytics/

Seleshi Sisaye, (2013) "The development of sustainable practices in complex organizations: Implications and potentials for integration into the accounting curriculum", World Journal of Entrepreneurship, Management and Sustainable Development, Vol. 9 Issue: 4, pp.223-245, https://doi.org/10.1108/WJEMSD-01-2013-0010

Stefan Bunea (2017) "The Contribution of Accounting Disciplines to Developing Professional and Personal Skills", SEA - Practical Application of Science, Vol. V, Issue $15 \quad$ (3/2017), http://seaopenresearch.eu/Journals/articles/SPAS_15_16.pdf 
Stuart Manson, Sean McCartney, Michael Sherer, (2001) "Audit automation as control within audit firms", Accounting, Auditing \& Accountability Journal, Vol. 14 Issue: 1, pp.109-130, https://doi.org/10.1108/09513570110381097

Tracey McDowall, Beverley Jackling, (2010) "Attitudes towards the accounting profession: an Australian perspective", Asian Review of Accounting, Vol. 18 Issue: 1, pp.30-49, https://doi.org/10.1108/13217341011045999

Vickram Sahai, Arvind Kumar Jain, P.C. Bahuguna, (2014) "Bridging the gap - interpersonal communication orientation to improving customer service", Industrial and Commercial Training, Vol. 46 Issue: 4, pp.209-219, https://doi.org/10.1108/ICT-10-2013-0070

Zabihollah Rezaee, (2004) "Restoring public trust in the accounting profession by developing anti-fraud education, programs, and auditing", Managerial Auditing Journal, Vol. 19 Issue: 1, pp.134-148, $\underline{\text { https://doi.org/10.1108/02686900410509857 }}$ 